Pakistan Journal of Education

Vol.37, No.1, 2020, 45-60

\title{
Demographic Variables and Emotional Labor of Public Sector School Leaders
}

\author{
Tahira Bibi* \\ Nasir Mahmood**
}

\begin{abstract}
Emotional Labor theory of Hochschild, 1983 and Grandey, (2000, 2015 $\&$ 2017) provided the basis of the current research that gives the regulation of emotions at workplace the two dimensions of EL as Surface Acting and Deep Acting level of the school leaders. Emotional Labor Measurement Scale for School Leaders (ELMS-SL) was used to measure the EL level of the public sector school leaders. Multi stage sampling technique was used to select the sample of 376 school leaders working in public sector secondary schools of the Punjab province. The core objective of the research was to measure the EL level and the contribution of demographic variables (gender, mode of job induction, marital status and work experience) towards the emotional regulation status through suppression of emotions and modification of feelings. Data were analyzed by using descriptive statistics, as well as t-tests, and ANOVA tests. The results revealed that public sector school leaders are practicing emotional labor. EL practices between male and female showed significant difference, whereas mode of induction, marital status and job experience were non-significant differences on EL.
\end{abstract}

Keywords: emotional labor, surface acting, deep acting, school leaders, demographic variables

\footnotetext{
* Lecturer in EPPSL Department, Allama Iqbal Open University, Islamabad, Email: tahira.naushahi@aiou.edu.pk ** Corresponding author; Professor, Faculty of Education AIOU Islamabad, Email: nasir.mahmood@aiou.edu.pk
} 


\section{Introduction}

Emotional labor being a critical component is fundamental to public management practices and services department. At work place, employees manage personal and other's emotions while interacting with multi stakeholders. Management of these emotions are observed and monitored. Management of emotion at work place through dramaturgical techniques is known as emotional labor. Employees mask their feelings and pass on the expected expressions or in some cases they manage to change their feeling as genuine (Grandey \& Melloy, 2017). Emotional labor as a process affects the employee's well-being and organizational performance.

In literary terms "Emotional Labor" (EL) is a term collectively used for emotional management and emotional work at work place. Initially EL was defined by Hochchild as "management of feeling to create a publicly observable facial and bodily display" (Hochsclid, 1983, p. 7). She writes it in her book The Management of Heart (1983), emotions as an exchange value and EL is sold for a wage. As an employee in any service or profession, the work done with emotion as a part of occupation is also called emotional labor. Emotions here become a commodity (A Dictionary of Sociology, 1998).

Emotional labor is a double-edged sword as it can increase the personal well-being of the employee by fulfilling task requirements and task effectiveness. The negative aspects of emotional labor are more inflicting on an individuals' mental and physical well-being. Hochschild, (1983) suggested that it can be difficult to manage an expression with a smile while dealing with difficult customers. Emotional demands and associated labor are fundamental aspects of the job of school heads and, given their potential to interfere with both individual and school functioning, need more research attention (Maxwell \& Riley, 2016).

The position of School leaders' is multifaceted, as they are dealing with administrators, monitoring teams, learners, educators, non-teaching staff, associations, parents, and community members and pressure groups on a regular basis. To communicate with such drivers and multiple stakeholders, they need to manage their and others emotions. At their work place, they hide their feelings, express expected expressions or change their feeling to appear more genuine in the performance as a school leader. School leaders' EL may have positive and negative effects on their well-being as employee and on their organizational performance.

The Government of Pakistan has initiated technical, financial, professional support to develop and enhance the capacity of public sector school leaders, so that the educational system may work effectively and 
efficiently. Therefore, expected contribution of school leaders in organizational performance and visible change in public sectors schools is required to dig out their psychosocial aspect i.e. emotional management as a responsibility of school leaders in the context of their work environment. There can be various contributing factors such as demographic, political, social, economic, financial and psychological which affect an employee's well-being and organizational performance. Among these factors; EL of educational leaders and their effects require serious consideration for in-depth study. EL of school leaders plays an important role in a school's performance.

This study was planned to get an in-depth insight into the level of emotional labor and the contribution of demographic variables such as gender, marital status, work experience and mode of induction for the role of secondary school head as its determent of EL of public sectors schools leaders.

There are many factors that affect emotional labor. These factors include dynamic variables and static variables. There are numerous inconsistent conclusions in the present studies, which need to be further investigated.

\section{Potential Contribution of the Study}

To have an in depth view into the effects of emotional labor on school leaders, this study is of value in the subject of emotions in the workplace of school leaders. The study will open up debatable factors about numerous inconsistent conclusions in the existing studies on the basis of demographic variables as potential determents of emotional labor in educational sector especially public sector schools.

\section{Objectives of the Study}

The objectives of the study were:

1. to measure the emotional labor level of the public sector school leaders.

2. to find the demographic variable differences as determents of the level of emotional labor practiced by school leaders.

\section{Research Questions/Research Hypothesis}

1.1 What was the level of emotional labor of the school leaders?

1.2 What was the surface acting level of school leaders?

1.3 What was the deep acting level of school leaders? 
1.4 What was the difference between EL,SA and DA level of School leaders on the basis of gender?

1.5 What wasthe difference between EL, SA and DA level of School leaders on the basis ofmode of induction?

1.6 What was the difference between EL, SA and DA level of School leaders on the basis of work experience as a head?

1.7 What was the difference between emotional labor of school leaders on the basis of marital status?

\section{Review of the Literature}

Three decades ago, emotions were a neglected phenomenon of study at workplace but in the current scenario, it is an important and interesting area in occupational health psychology; organizational behavior. The term "Emotional Labor (EL)" was used for the first time by the sociologist "Hochschild" in 1983 in her book "The Managed Heart: The Commercialization of Human Feeling as Management and Modification of Emotion as Part of Work Role for Wages" (Grandy, 2000; Grandey \& Gabriel, 2015; Maxwell \& Riley, 2016 \& Grandey \& Melloy, 2017). In view of Hochshild's (1983) work, Grandey (2015) represented EL into three occupational categories i.e. emotional requirements, emotional regulation, and emotional performance. The first one relates to employees' perspective of their job display rules. Second one is a socioemotional demand of the work place and the third one is about observable expressions (Grandey \& Gabriel, 2015). EL is used to manage inner emotions and falsify the expression of; displaying emotions needed to specifically conform to organizational requirements, expectations and norms. This is done to obtain appropriate responses on the various stakeholders to achieve or adhere to the goals of the organization. Berkovich \& Eyal (2015), identify the association of EL of educational leadership as: "macro- and micro-contextual factors" as well as gender relations and lack of supervisor support; "leadership role factors" such as loneliness; and "mission-related factors" such as ongoing experiences of social injustice. Other caring professions have all demonstrated contrary levels of EL (Maxwell \& Riley, 2016).

EL is being studied as Surface Acting (SA) Response-Focused Emotional regulation (Grandey \& Melloy, 2017) which covers both the self-consciousness and build-up of emotions. Employees mask their own feelings and pass on the anticipated expression and the deep acting (DA). DA is a process through which employees put efforts to change feeling to appear more genuine in the performance, but perhaps losing their true feelings in the process (Grandey \& Melloy, 2017). Personal 
accomplishment has demonstrated positive, negative and no significant associations with DA. So we can claim that there are mixed effects of DA (Maxwell \& Riley, 2016).

Surface acting could be seen as "faking in bad faith", while deep acting was "faking in good faith" (Grandey, 2003 \& Hochschild, 1983). Emotional regulation is a guiding theory for understanding the mechanism by which emotional labor may be stressful to individuals but still be useful to the organization (Grandey, 2000). Emotional labor can best be described in term of frequency of emotional labor. (Morris, 1997; Grandy, 2000) Surface acting taxes surface actors' bodies and thus have a detrimental effect on their well-being (Grandey, 2000; Gross, 1998). Deep acting and displays of genuine emotions are positively related to deep actors; job satisfaction. (Hochschid, 1983; Wang, 2011).

There is a positive correlation between seniority and teachers' DA(Ye \& Chen, 2015; Liu, 2007).Teachers who have a longer work experience are practicing DA more.

Liu (2007) found in his study that there is no significant difference between SA and DA between male and female teachers of primary and middle schools. He further explores that there is a significant difference in the expression of naturally felt emotions between male and female, teachers. Chen (2010) measured the EL of colleges' and universities' teachers and found that there are no significant differences in EL (included SA, DA and NE) of male and female. This study further revealed that the SA of male teachers is higher than that of the female, and the expression of naturally felt emotions of the female was significantly higher than that of male.

Liu X. , (2017) identifies the frequency level of DA in the respondents of his study. It was found that gender differences were significant in SA whereas significant differences were found in DA with respect to age and educational level. This study was about frontline employees.

Tian et al. (2009)'s study was on special education teachers. It is revealed that there was no significant difference in the EL of the male and female. Further it was found that the SA and the DA of the male were lower than that of female. So we can see that gender affects teachers' emotional work, but the role of gender may be different for different teachers' groups. Chen's (2010) research reveals that the SA of married individuals was significantly lower than that of unmarried individuals. The expression of naturally felt emotions of single individual was significantly lower than that of the married individual. In addition, Liu (2007)'s study identified that the natural felt emotions of the married teachers at primary and secondary schools was higher than the unmarried 
teachers. It was also found that there was no significant difference between SA and DA of married and unmarried teachers.

Gönül Şener , (2014) conducted a study on the primary school teachers in Turkey. They reported in their article that there exists no significant difference among teachers in different demographic variables such as gender, marital status, field of study and educational level, whereas a statistical significant difference was found in the experience variable.

In brief, there are many factors that affect emotional labor. These factors include dynamic variables and static variables. There are numerous inconsistent conclusions in the present studies, which need to be further investigated.

\section{Methodology}

The current study adopted quantitative approach to study the effect of one variable on other variables (Creswell, 2012). Furthermore, this study followed the causal-comparative research design (Fraenkel, Wallen, \& Hyun, 2011) and measurement scale was used to find the answers of research questions and data collection.

\section{Population}

The population of the study was the entire 3,412 male, 2900 female head teachers of Government secondary schools of the Punjab province (School Education Department, 2018).

\section{Sampling}

A Multi stage random sampling technique was applied to collect the true representatives of the study population. At first, stratified random sampling technique was applied to select the 19 out of 36 districts of Punjab. At the second stage, sample districts were divided into two strata of male and female and at the third stage, the sample was drawn from the male and female strata and 376 school heads were selected as representatives of the schools leaders of the public sector secondary schools.

\section{Instrument of the Study}

Self-developed emotional labor measurement scale for school leaders (ELMS-SL) consisting of ten situational statements was used and each statement was measured through six statements about the SA and DA on 
five points Likert-type scale (Never 1, Seldom 2, Occasionally 3, Regularly 4, Always 5).

\section{Validity and Reliability}

The validity of the ELMS-SL was ensured through experts' opinions and CVI (Content Validity Index) statement having I-CVI $=0.86$ was taken as part of the scale. Scale content validity Index of the ELMS-SL was $\mathrm{S}-\mathrm{CVI} / \mathrm{UA}=0.842$ and $\mathrm{S}-\mathrm{CVI} / \mathrm{Ave}=0.96$ which is acceptable (Polit $\&$ Beck, 2006). The reliability of the scale was measured through Cronbach's Alpha coefficient (Fraenkel, Wallen, \& Hyun, 2011).Cronbach's Alpha of the ELMS-SL was $P>0.60$ (0.945)Subconstruct SA and DA were 0.938 and 0.951 respectively, showed the internal consistency of the statement. To test the reliability of the scale, 378 responses were taken from the public sector school leaders, who were not part of the sample of the study.

\section{Data Analysis}

Descriptive (mean and standard deviation) and inferential statistics (independent sample t-test and one-way ANOVA) were applied by using Statistical Package for Social Sciences (IBM-SPSS-20) to analyze the data. The results are shown in the following tables.

Table 1

Descriptive Statistics of the state of emotional labor of school leaders

\begin{tabular}{llcc}
\hline Sr & Variable & Mean & St.d \\
\hline 1 & Surface Acting & 2.97 & 0.64 \\
2. & Deep Acting & 2.87 & 0.62 \\
3. & Emotional Labour & 2.94 & 0.58 \\
\hline
\end{tabular}

$(\mathrm{N}=376)$

Table 1 shows the mean value of the EL level of the school leaders. Measurement scale was developed on five point scale and 1 point was given to the "never" and "always" scored 5. Over all EL of the school leaders' Mean= 2.94 (st.d=0.58) that showed school leaders are doing EL but occasionally. Two sub constructs of the EL i.e. SA Mean= 2.97 (st.d=0.64), DA Mean= 2.87 (st.d=0.62). The Mean score of the SA, DA 
and EL showed that school heads were practicing EL, SA and DA occasionally.

Table 2

Comparison of Emotional labor level of the school leaders (Gender)

\begin{tabular}{lccccccc}
\hline Variable & Group & $N$ & $M$ & St.d & $T$ & $d f$ & $P$ \\
\hline $\begin{array}{l}\text { Surface } \\
\text { Acting }\end{array}$ & Male & 194 & 2.93 & 21.11057 & & 374 & $.004^{*}$ \\
& Female & 182 & 3.02 & 16.93772 & -1.432 & 365.324 & \\
& Male & 194 & 2.89 & 19.27055 & & 374 & $.221^{*}$ \\
$\begin{array}{l}\text { Deep } \\
\text { Acting }\end{array}$ & Female & 182 & 2.87 & 17.73724 & -.218 & 373.867 & \\
& Male & 194 & $2 . .91$ & 38.33674 & & 374 & $.005^{*}$ \\
$\begin{array}{l}\text { Emotional } \\
\text { Labor }\end{array}$ & & & & & & & \\
& Female & 182 & 2.95 & 31.11743 & -.669 & 366.517 & \\
\hline$P<.05 *$ & & & & & & &
\end{tabular}

Table 2 gender is a dichotomous nominal variable. To compare the mean of the SA, DA and EL of the female school leaders with the male school leaders, an independent sample t-test is an appropriate statistic. The first three rows of the table 2 provide the descriptive statistics (frequency mean and standard deviation) on the SA, DA and EL variable for the men, and for women in the study i.e., $(\mathrm{N}=194+182)$, the 194 men got average at 2.93 level of SA, average 2.89 at DA and 2.91 at over all EL. Whereas the 182 female got average at 3.02 level of SA, 2.87 at DA and 2.95 at over all EL. The p value of the overall EL and SA variables are $\mathrm{p}<.05(.005$, and .004) so, there is a significant difference between the Emotional labor level of the male and female school leaders. Whereas, the P value of the DA variable is $\mathrm{p}>.05(.221)$ so, there is no significant difference between DA level of male and female school leaders. 
Table 3

One-Way Analysis of variance EL level of the school leaders (Mode of selection for current position)

\begin{tabular}{|c|c|c|c|c|c|c|}
\hline Variable & Categories & $N$ & $M$ & St.d & $F$ & Sig \\
\hline \multirow[t]{3}{*}{ Surface Acting } & Promotion & 159 & 2.63 & 20.014 & .518 & .596 \\
\hline & $\begin{array}{l}\text { Direct } \\
\text { induction }\end{array}$ & 206 & 2.69 & 19.094 & & \\
\hline & $\begin{array}{l}\text { Deputation \& } \\
\text { any other }\end{array}$ & 11 & 2.88 & 5.212 & & \\
\hline \multirow[t]{3}{*}{ Deep Acting } & Promotion & 159 & 2.84 & 18.902 & .572 & .565 \\
\hline & $\begin{array}{l}\text { Direct } \\
\text { induction }\end{array}$ & 206 & 2.91 & 18.627 & & \\
\hline & $\begin{array}{l}\text { Deputation \& } \\
\text { any other }\end{array}$ & 11 & 2.90 & 8.105 & & \\
\hline \multirow[t]{3}{*}{ Emotional Labor } & Promotion & 159 & 2.88 & 36.210 & .621 & .538 \\
\hline & $\begin{array}{l}\text { Direct } \\
\text { induction }\end{array}$ & 206 & 2.95 & 34.900 & & \\
\hline & $\begin{array}{l}\text { Deputation and } \\
\text { Any other }\end{array}$ & 11 & 2.96 & 10.634 & & \\
\hline
\end{tabular}

$P>.05 *$

The first parts of the table 3 reveal the descriptive statistics for three groups of the school leaders of the study into frequency, mean and standard deviation. Mean and standard deviation of the all three groups in SA, DA and EL show the difference in the group. But this difference is statistically not significant because $\mathrm{P}$ value of the groups shows $\mathrm{P}>.05$, $(.596, .565$ and .538$)$ so, statistically no significant difference existed between all three nominal groups. 
Table 4

One-Way Analysis of variance EL of school leaders (Job Experience)

\begin{tabular}{|c|c|c|c|c|c|c|}
\hline \multicolumn{7}{|l|}{ Variable } \\
\hline & Categories & $N$ & $M$ & St.d & $F$ & $P$ \\
\hline \multirow[t]{6}{*}{ Surface Acting } & Less than 1 year & 10 & 3.07 & 11.153 & \multirow[t]{6}{*}{.354} & \multirow[t]{6}{*}{.879} \\
\hline & Less than 5 years & 48 & 3.02 & 19.383 & & \\
\hline & Less than 10 years & 78 & 3.00 & 18.938 & & \\
\hline & Less than 15 years & 52 & 3.02. & 19.635 & & \\
\hline & Less than 20 years & 31 & 2.91 & 20.702 & & \\
\hline & 20 years above & 157 & 2.63 & 19.466 & & \\
\hline \multirow[t]{6}{*}{ Deep Acting } & Less than 1 year & 10 & 2.96 & 15.469 & \multirow[t]{6}{*}{.406} & \multirow[t]{6}{*}{.844} \\
\hline & Less than 5 years & 48 & 2.90 & 19.802 & & \\
\hline & Less than 10 years & 78 & 2.93 & 18.268 & & \\
\hline & Less than 15 years & 52 & 2.90 & 20.110 & & \\
\hline & Less than 20 years & 31 & 2.77 & 17.802 & & \\
\hline & 20 years above & 157 & 2.86 & 18.172 & & \\
\hline \multirow[t]{6}{*}{ Emotional Labor } & Less than 1 year & 10 & 3.01 & 23.238 & \multirow[t]{6}{*}{.394} & \multirow[t]{6}{*}{.853} \\
\hline & Less than 5 years & 49 & 2.96 & 37.040 & & \\
\hline & Less than 10 years & 77 & 2.96 & 34.203 & & \\
\hline & Less than 15 years & 52 & 2.97 & 37.006 & & \\
\hline & Less than 20 years & 31 & 2.84 & 37.065 & & \\
\hline & 20 years above & 157 & 2.90 & 34.581 & & \\
\hline
\end{tabular}

$p>0.05^{*}$

Table 4 shows the $\mathrm{P}$ value of the six groups' distribution on the bases of job experience of the school leaders. As the table showed p>.05 i.e $.879, .844, .853$ so the null hypothesis was accepted and there is no significant difference amongst the groups on the basis of number of years in work experience.

\section{Table 5}

Comparison in the dimensions of EL level of the school leaders (Marital status)

\begin{tabular}{llcccccc}
\hline Variable & Group & $N$ & $M$ & St.d & $T$ & $d f$ & $P$ \\
\hline Surface Acting & Married & 321 & 2.97 & 0.63 & -.351 & 374 & .215 \\
& Unmarried & 55 & 3.00 & 0.69 & & 70.404 & \\
Deep Acting & Married & 321 & 2.89 & 0.61 & .099 & 374 & .156 \\
& Unmarried & 55 & 2.87 & 0.67 & & 70.425 & \\
Emotional Labor & Married & 321 & 2.92 & 0.58 & -.140 & 374 & .261 \\
& Unmarried & 55 & 2.94 & 0.61 & & 71.878 & \\
\hline
\end{tabular}

$p>0.05^{*}$ 
Table 5 showed the data analysis of the two groups. The groups were divided on the basis of school leaders' marital status. The $P$ value is greater than the .05 in SA, DA and over all EL level of the school leaders. So the null hypothesis is accepted that there is no significant difference between the school leaders SA, DA and EL level of the school leaders on the basis of their difference in marital status.

\section{Results/ Findings}

The ELMS-SL comprised of sixty statements. The findings based on the responses of the school leaders and statistical analyses of the data against these statements are given below:

1. School leaders were practicing EL, SA and DA. (Table 1)

2. There was a significant difference in SA and EL level of school leaders on the basis of gender. (Table 2)

3. There was no significant difference in DA of school leaders on the basis of gender.( Table 2)

4. There was no significant difference in EL, SA and DA level of school leaders on the basis of their mode of induction i.e. promotion, direct induction, deputation or any other. (Table 3)

5. There was no significant difference in EL, SA and DA level of school leaders on the basis of their work experience. (Table 4)

6. There was no significant difference in EL, SA and DA level of school leaders on the basis of marital status. (Table 5)

\section{Conclusion/ Discussion}

The existing levels of emotional labor of school leaders revealed that School leaders are practicing EL as Maxwell \& Riley, 2016 revealed through their study. Further it was found that majority of female school leaders are practicing emotional labor at their workplace when they go through the following situations than male school leaders.

- dealing with people in different context, experience negative emotions (i.e. fear, and anger)

- due to visit of monitoring teams,

- conflict arises,

- higher authorities pressurize to achieve objectives without sufficient support, 
- experience a difficult situation due to teachers, students, community and higher authority,

- deal with low performing teachers and students,

- during official meetings, discussions and decision making,

- when there is a shortage of time, heavy workload, unlimited working hours to complete the task and they are held answerable to higher authorities,

- when political agents/community pressure groups interfere in their professional duties,

- when encountering a behavioral problem (with teachers, students, community or any other individual at workplace)

Furthermore, the results of the analysis revealed that the female school leaders showed a higher rate of practicing SA level strategy than the male school leaders where as both are at the same level of practicing the DA strategy in response to emotional situations. Gender affects EL as supported by many authors (Hochschid, 1983; Wharton \& Erickson, 1993; Kruml \& Geddes, 1998; Timmers, Fischer, \& Manstead, 1998 \& Grandy, 2000). Liu X. , (2017) identifies the high frequency level of DA in the respondences of the study. It was found that gender differences were significant in SA whereas significant differences were found in DA of age and educational level. This study was about frontline employees.

Public sector school leaders were practicing the emotional labor occasionally but not regularly. Results showed that their current SA, DA and EL practices increased with having less job experience rather than the experienced school leaders but statically did not prove a significant difference among the groups on the basis of job experience as a head of institution. School leaders who had received the school headship through direct induction were high in EL than the promoted ones and other mode of getting headship. But statistically significant difference did not show through data analysis.

These results are not similar to the findings of (Brown, 2011) which revealed that the classroom leaders who are more experienced showed increased levels of deep acting than teachers newer to the profession.

The results of the study showed that on the basis of marital difference EL, SA and DA no statisticaly significant differences existed among the respondents of the study. As Gönül Şener M. B., (2014) 
conducted a study on the primary school in Turkey. They reported in their study the same finding about marital status being adeterment of EL.

It was concluded that the public sector secondary school leaders are practicing SA, DA and EL. However, according to the measurement scale SA, DA and EL were not always a regular practice but rather practiced occasionally.

Based on the findings, it was concluded that gender affected the EL level of the public sector school leaders whereas DA strategy practices were not affected by gender. The variable modes of induction as school leaders (i.e. promotion, direct induction, deputation and any other),job experience and marital status differences did not affect the EL level of the public sector school leaders. 


\section{References}

Berkovich, I., \& Eyal, O. (2015). Educational Leaders and Emotions:An International Review of Empirical Evidence 1992-2012. Review of Educational Research, 85 (1), 129-167.doi: 10.3102/ 0034654314550046

Brown, E. L. (2011, March 25). Emotion Matters: Exploring the Emotional Labor of Teaching. University of Pittsburgh School of Education .

Chen, X. N. (2010). The Empirical Study of Yong University Teachers' Emotional Labor. Heilongjiang Researches on Higher Education, 12 (2010), 23-26

Cordes, C. L. (1993). a review and integration of research on job burnout. Academy of Management Review18 (4), 621-656.

Creswell, J. w. (2012). Educational Research . United States of America: Edwards Brothers.

Fraenkel, J. R., Wallen, N. E., \& Hyun, H. H. (2011). How to Design and Evaluate Research in Education (Eighth ed.). New York, USA: The McGraw-Hill Companies Inc.,1221 Avenue.

Grandey, A. A. (2000). Emotion Regulation in the Workplace: A New Way. Journal of Occupational Health Psychology to Conceptualize Emotional Labor , 5 (1), 95-110. doi:10.1037//1076-8998.5.1.95

Grandy, A. A. (2003). When "the Show Must Go on": Surface Acting and Deep Acting as Determinants of Emotional Exhaustion and PeerRayed Service Delivery. Academy of Management Journal , 46 (1), 86-96.

Grandey, A. A. (2015). Smiling for a Wage: What Emotional Labor Teaches Us About Emotion Regulation. Psychological Inquiry;An International Journal for Advancement of Psychological Theory, 26 (1) 54-60.doi: 10.1080/1047840X.2015.962444

Grandey, A. A., \& Gabriel, A. S. (2015). Emotional Labour at a Crossroads: Where do we go from here? The annual review of organizational psychology and organizational behavior, 2 (2015), 323-349. doi:10.1146/annurev-orgpsych-032414-111400 
Grandey, A. A., \& Melloy, R. C. (2017). The state of the heart: emotional labor as emotion regulation reviewed and revised. (P. Y. Chen, Ed.) Journal of Occupational Health Psychology,22(3), 407422 http://dx.doi.org/10.1037/ocp0000067

Gross, J. (1998). The emerging field of emotion regulation: An integrative review. Review of General Psychology. , 2(3), 271-299.

Gönül Şener, M. (2014). Teaching and Emotional Labor. American International Journal of Social Science, 3(5), 111-119.

Hochschid, A. R. (1983). The managed heart. California, United States of America: University of California Press.

Kruml, S., \& Geddes, D. (1998). Exploring the dimensions of emotional labor: The heart of Hochschild's work. First conference of emotions in organizational life. San Diego, California United States America.

Liu, X. (2017). Emotional Labor Strategy of Hotel Frontline Employees: The Antecedents and Consequences. Journal of Service Science and Management , 10 (5) 425-436.

Liu, Y., \& Zhang, D. (2015, January). Development of Questionnaire on Emotional Labor among Primary and Secondary School Teachers. Journal of Education and Training Studies, 3 (1) 46-55.

Liu, Y. L. (2007). Research on Teacher's Emotion Work in Elementary and Middle School.

Ph.D. Thesis, Chongqing: Southwest University.

Maxwell, A. (2016). Synchronous and Longitudinal Models of Emotional Labour and Occupational Health. Monash University, Faculty of Education. Melbourne: Monash University.

Maxwell, A., \& Riley, P. (2016). Emotional demands, emotional labour and occupational outcomes in school principals: Modelling the relationships. Educational Management Administration \& Leadership ,45(3) 484-502.doi:10.1177/1741143215607878

Morris, J. A., \& Feldman , D. C. (1996). The Dimensions, Antecedents, and Consequences of Emotional Labor. Acadamy of Management Review, 21 (4), 986-1010. 
Morris, J. A. (1997). Managing emotion in the workplace. Journal of Managerial Issues , 9(3), 257-274.

Punjab, G. (n.d.). http://schoolportal.punjab.gov.pk/census/schoolcensusNew.htm. Retrieved 01 17, 2018, from School education department Government of Punjab : http://schools.punjab.gov.pk/

Tian, X. H., Zhou, H. Y., \& Chen, D. W. (2009). A Survey on Emotional Labor of Special Education Teachers. Chinese Journal of Special Education (Monthly), 2009 (8), 50-56.

Timmers, M., Fischer, A. H., \& Manstead, A. R. (1998). Gender motives for regulating emotions. Personality and social psychology bulletin, 24(9), 974-985.

Wang, G. (2011). What role does leaders' emotional labor play ineffective leadership? An empirical examination. University of Iowa.

Wharton, A. S., \& Erickson, R. J. (1993). The effective consequences of service work: Managing emotions on the job. Work and Occupations, , 20(2), 205-232.

Ye, M., \& Chen, Y. (2015). A Literature Review on Teachers' Emotional Labor. Creative Education, 6(20), 2232-2240.

\section{Citation of this Article:}

Bibi, T., \& Mahmood, N. (2020). Demographic variables and emotional labor of public sector school leaders. Pakistan Journal of Education, 37 (1), 45-60. 